\title{
Negative Effect of Immediate Sunitinib Interruption on Survival in Patients With Metastatic Renal Cell Carcinoma
}

\author{
RYO ISHIYAMA ${ }^{1}$, HIROKI ISHIHARA ${ }^{1}$, TSUNENORI KONDO ${ }^{2}$, TOSHIO TAKAGI ${ }^{1}$, \\ KAZUHIKO YOSHIDA ${ }^{1}$, JUNPEI IIZUKA ${ }^{1}$, HIROHITO KOBAYASHI ${ }^{2}$, \\ MASAYOSHI OKUMI ${ }^{1}$, HIDEKI ISHIDA ${ }^{1}$ and KAZUNARI TANABE ${ }^{1}$ \\ ${ }^{1}$ Department of Urology, Tokyo Women's Medical University, Tokyo, Japan; \\ ${ }^{2}$ Department of Urology, Tokyo Women's Medical University Medical Center East, Tokyo, Japan
}

\begin{abstract}
Background: Treatment modification due to adverse events reduces the dose intensity in cancer treatment. The prognostic impact of sunitinib treatment interruption within the initial period of therapy for metastatic renal cell carcinoma $(m R C C)$ remains unknown. Patients and Methods: We retrospectively evaluated 97 patients with $m R C C$ treated with first-line sunitinib treatment. The patients were classified into two groups according to the presence of treatment interruption (TI) within the initial two cycles. The prognostic impact of TI was analyzed using the Kaplan-Meier method and log-rank test, and multivariate analyses using the Cox proportional hazard model. Results: Thirty-eight patients (39.2\%) experienced an immediate TI. The median progression-free (PFS) and overall (OS) survival were significantly shorter in patients with a TI than in those without (PFS= 6.54 vs. 11.3 months, $p=0.0246 ; O S=16.9$ vs. 30.0 months, $p=0.0420)$. Multivariate analyses for PFS and OS showed that TI was an independent factor predicting poorer PFS (hazard ratio $(H R)=1.93, p=0.0141)$ and $O S(H R=2.09$, $p=0.0102)$. In addition, the relative dose intensity within the initial two cycles was significantly lower in patients with a TI than in those without $(52.7 \%$ vs. $75.0 \%, p<0.0001)$. Conclusion: This study showed the significantly negative effect of immediate TI on survival of patients under sunitinib treatment for mRCC. Therefore, the careful monitoring of patient tolerability is required in order to maintain therapeutic efficacy in the early phase of sunitinib treatment.
\end{abstract}

This article is freely accessible online.

Correspondence to: Hiroki Ishihara, Department of Urology, Tokyo Women's Medical University, 8-1 Kawada-cho, Shinjuku-ku, Tokyo 162-8666, Japan. Tel: +81 338101111, Fax: +81 358556319, e-mail: ishihara.hiroki@twmu.ac.jp

Key Words: RCC, TKI, tyrosine kinase inhibitor, adverse event, toxicity, dose-limiting toxicity.
Treatment modification, including schedule and dosage change, is needed in a subset of patients with drug-induced adverse events (AEs) during cancer treatment. These doselimiting toxicities (DLTs) reduce the dose intensity, resulting in impaired therapeutic efficacy (1). Therefore, it is important to balance treatment intensity and patient tolerability.

Sunitinib is a molecular-targeted agent commonly used for treatment of metastatic renal cell carcinoma (mRCC) $(2,3)$; however, an unsolved usage issue is its strong drug-induced toxicity $(4,5)$. Several studies reported that the reduced dose intensity caused by DLTs in the early phase of sunitinib treatment resulted in poor prognosis (6-9). However, clinical information regarding the prognostic association of treatment modification types, especially treatment interruption (TI) expected to cause a significant decrease in dose intensity, is limited.

Therefore, we retrospectively investigated the effect of treatment interruption developing within the early phase of sunitinib therapy on survival in patients with mRCC.

\section{Patients and Methods}

Study design. Between January 2007 and June 2018, 132 patients were treated with first-line sunitinib for mRCC (Figure 1). Of the 132 patients, two patients who had received cytokine therapy before sunitinib treatment were excluded, as were 26 patients whose sunitinib treatment was performed as neoadjuvant or adjuvant therapy. From the 104 remaining patients, seven patients whose data were unavailable owing to loss during follow-up where further excluded. The remaining 97 patients were evaluated in this singlecenter retrospective study.

The 97 patients were divided into two groups according to the presence of an immediate treatment interruption (TI); 38 and 59 patients were classified into the TI and without TI groups, respectively (Figure 1). We further classified the 59 patients in the no TI group according to the presence of an immediate dose reduction; 22 and 37 patients were classified into the dose reduction and no modification groups, respectively. In this study, patients with at least one interruption, regardless of the presence of dose reduction, were classified into the TI group. Patients categorized 


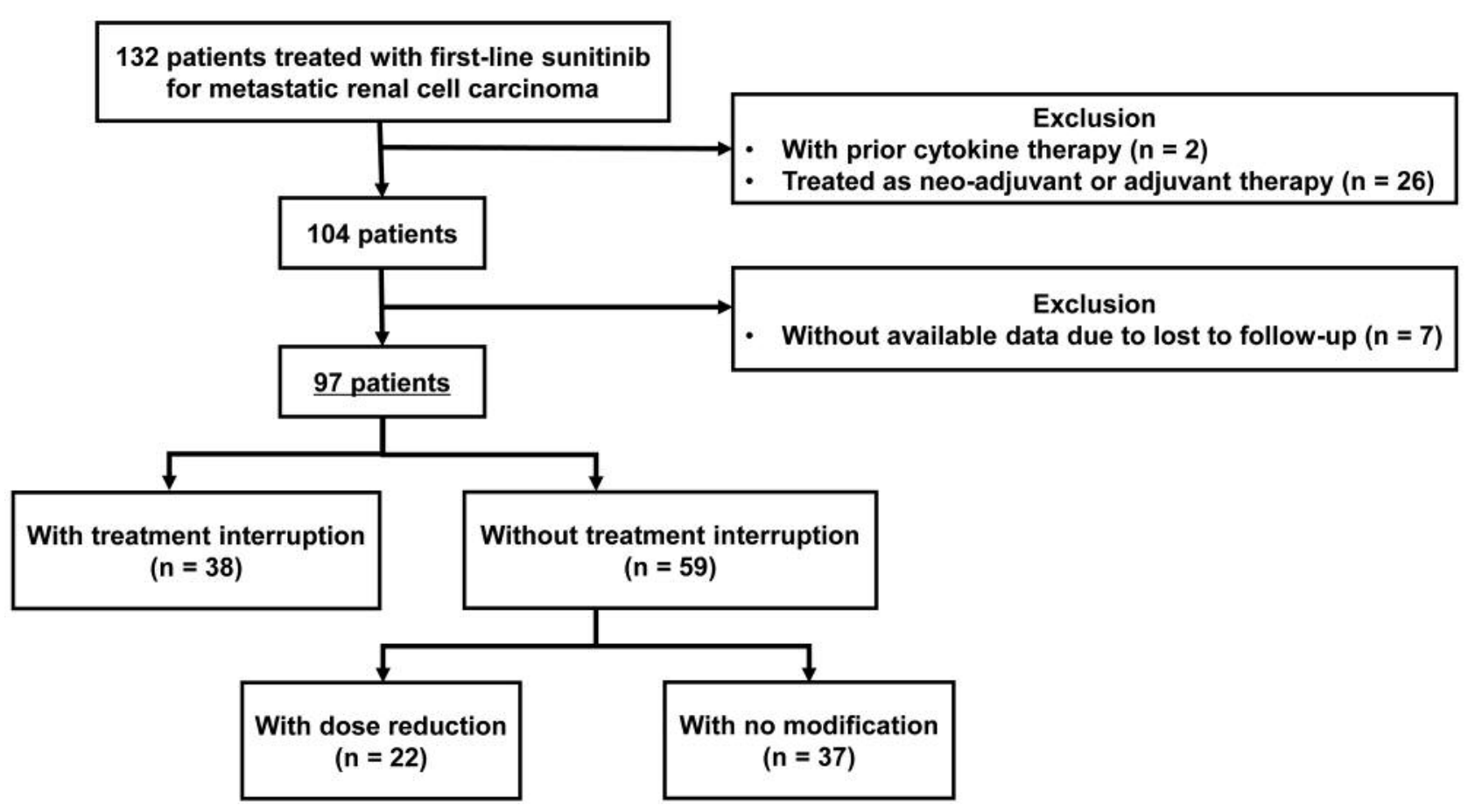

Figure 1. Patient selection and study design.

into the dose reduction group did not experience any TI during sunitinib therapy. All immediate treatment modification was defined as developing within the initial two cycles of sunitinib treatment.

All study procedures were approved by the Institutional Review Board of Tokyo Women's Medical University and were in accordance with the Declaration of Helsinki (ID: 4551).

Sunitinib treatment protocol. The sunitinib treatment protocol adopted at our Department was previously reported $(6,10)$. Briefly, we administered sunitinib under a 2-weeks-on/1-week-off treatment schedule for most patients based on our previous study $(6,11)$. The standard initial dose was $50 \mathrm{mg} /$ day. Reduction of the initial dose was considered when patients met the following criteria: (i) Age $>65$ years, (ii) serum creatinine level $>2.0 \mathrm{mg} / \mathrm{dl}$, and (iii) body weight $<50 \mathrm{~kg}$. When one of these three factors was present, the initial dose was reduced to $37.5 \mathrm{mg} /$ day. When two or more factors were present, the initial dose was reduced to $25 \mathrm{mg} /$ day. The dose was increased by $12.5 \mathrm{mg} /$ day until we determined the highest dose a patient was able to tolerate, although the dose never exceeded $50 \mathrm{mg}$ /day.

Treatment was continued until disease progression or intolerable AEs were observed.

Post-treatment follow-up scans obtained using plain or contrastenhanced computed tomography of the chest, abdomen, and pelvis were performed every 2-3 months of treatment according to the patient's condition, as previously reported (12).

$A E$ evaluation. AEs were assessed according to the Common Terminology Criteria for Adverse Events of the National Cancer Institute, version 4.0 (13), and treatment modifications, including reduction or interruption, were subsequently performed as necessary.
When a patient experienced multiple AEs, the highest grade of AE was recorded for each patient. Additionally, when a patient underwent both dose reduction and TI, the interruption was evaluated as a dose modification.

Statistical analysis. Continuous variables were analyzed using the Mann-Whitney $U$-test or the Kruskal-Wallis test, and categorical variables were analyzed using the chi-squared or Fisher's exact test. Progression-free (PFS) and overall (OS) survival were defined as the time from therapy initiation to the date of progression, and to the date of death from any cause, respectively. Survival was calculated using the Kaplan-Meier survival curve method and compared using the logrank test. Univariate and multivariate analyses using the Cox proportional hazard regression models were used to identify survival factors. The survival risk was expressed as a hazard ratio (HR) and 95\% confidence interval (CI). All analyses were performed using JMP software (version 14; SAS Institute Inc., Cary, NC, USA), and values of $p<0.05$ were considered statistically significant.

\section{Results}

Patient background. Table I shows the comparison of patient backgrounds according to TI presence. The female patient rate was significantly higher ( $44.7 \%$ vs. $22.0 \%, p=0.0182)$ and the frequency of patients on the 4-weeks-on/2-weeks-off treatment schedule had a tendency to be higher $(42.1 \%$ vs. $23.7 \%$, $p=0.0559)$ in patients with TI than in those without. In addition, the median RDI during the initial two cycles was significantly lower in patients with TI $[52.7 \%$ (95\% CI=37.5- 
Table I. Patient background information .

\begin{tabular}{|c|c|c|c|c|}
\hline & $\begin{array}{l}\text { Whole cohort } \\
\qquad(\mathrm{n}=97)\end{array}$ & $\begin{array}{c}\text { With treatment } \\
\text { interruption }(n=38)\end{array}$ & $\begin{array}{l}\text { Without treatment } \\
\text { interruption }(n=59)\end{array}$ & $p$-Value \\
\hline \multicolumn{5}{|l|}{ Age } \\
\hline Median (range) & $64(59.0-69.5)$ & $67(61.5-72.5)$ & $63(56-69)$ & 0.0269 \\
\hline$\geq 65$ Years & $47(48.5 \%)$ & $22(57.9 \%)$ & $25(42.4 \%)$ & 0.135 \\
\hline \multicolumn{5}{|l|}{ Gender } \\
\hline Male & $67(69.1 \%)$ & $21(55.3 \%)$ & $46(78.0 \%)$ & 0.0182 \\
\hline \multicolumn{5}{|l|}{ Histopathology } \\
\hline Clear-cell carcinoma & $70(72.2 \%)$ & $24(63.2 \%)$ & $46(78.0 \%)$ & $0.112 *$ \\
\hline Non-clear cell carcinoma & $27(27.8 \%)$ & $14(36.8 \%)$ & $13(22.0 \%)$ & \\
\hline Papillary renal cell carcinoma type II & $4(4.12 \%)$ & $2(5.26 \%)$ & $2(3.39 \%)$ & \\
\hline Clear-cell carcinoma with spindle cells & $8(8.25 \%)$ & $6(15.8 \%)$ & $2(3.39 \%)$ & \\
\hline Other/unknown & $15(15.5 \%)$ & $6(15.8 \%)$ & $9(15.3 \%)$ & \\
\hline \multicolumn{5}{|l|}{ MSKCC risk group } \\
\hline Favorable & $15(15.5 \%)$ & $6(15.8 \%)$ & $9(15.3 \%)$ & 0.960 \\
\hline Intermediate & $68(70.1 \%)$ & $27(71.1 \%)$ & $41(69.5 \%)$ & \\
\hline Poor & $14(14.4 \%)$ & $5(13.2 \%)$ & $9(15.3 \%$ & \\
\hline \multicolumn{5}{|l|}{ Prior nephrectomy } \\
\hline Yes & $85(87.6 \%)$ & $32(84.2 \%)$ & $53(89.8 \%)$ & 0.412 \\
\hline \multicolumn{5}{|l|}{ Treatment schedule } \\
\hline 4-weeks-on/2-weeks-off & $30(30.9 \%)$ & $16(42.1 \%)$ & $14(23.7 \%)$ & 0.0559 \\
\hline \multicolumn{5}{|l|}{ Initial dose } \\
\hline $50 \mathrm{mg}$ & $30(30.9 \%)$ & $11(29.0 \%)$ & $19(32.2 \%)$ & $0.927 * *$ \\
\hline $37.5 \mathrm{mg}$ & $50(51.6 \%)$ & $19(50.0 \%)$ & $31(52.5 \%)$ & \\
\hline $25 \mathrm{mg}$ & $17(17.5 \%)$ & $8(21.1 \%)$ & $9(15.3 \%)$ & \\
\hline \multicolumn{5}{|l|}{ Site of metastasis } \\
\hline Multiple & $48(49.5 \%)$ & $20(52.6 \%)$ & $28(47.5 \%)$ & 0.619 \\
\hline \multicolumn{5}{|l|}{ Liver metastasis } \\
\hline Yes & $13(13.4 \%)$ & $7(18.4 \%)$ & $6(10.2 \%)$ & 0.244 \\
\hline \multicolumn{5}{|l|}{ RDI within initial 2 cycles } \\
\hline Median (95\% CI)) & $68.8(51.5-76.3)$ & $52.7(37.5-62.5)$ & $75.0(65.7-81.3)$ & $<0.0001$ \\
\hline \multicolumn{5}{|l|}{ Follow-up period } \\
\hline Median (IQR) & $8.84(3.45-18.6)$ & $12.7(4.57-25.9)$ & $24.5(11.0-38.9)$ & 0.0040 \\
\hline
\end{tabular}

CI: Confidence intervaI; IQR: interquartile range; MSKCC: Memorial Sloan Kettering Cancer Center. *Clear-cell carcinoma $v s$. non-clear-cell carcinoma. $* * \geq 37.5 v s .<37.5 \mathrm{mg}$.

$62.5 \%) v s .75 .0 \%(95 \% \mathrm{CI}=65.7-81.3 \%), p<0.0001]$ than in those without. There was no significant difference in other factors including age, cancer histopathology, Memorial Sloan Kettering Cancer Center (MSKCC) risk, prior nephrectomy, initial dose, sites of metastases, or presence of liver metastasis (all $p>0.05$ ). The median follow-up duration was significantly shorter in patients with TI $[12.7$ (95\% CI=4.57-25.9) vs. 24.5 (95\% CI=11.0-38.9) months, $p=0.0040]$ than in those without

Survival according to treatment modification. Figure 2 shows that median PFS and OS were significantly shorter in patients with TI than those without $[\mathrm{PFS}=6.54(95 \%$ $\mathrm{CI}=2.76-10.4) \quad v s . \quad 11.3 \quad(95 \% \quad \mathrm{CI}=8.65-20.7) \quad$ months, $p=0.0246 ; \mathrm{OS}=16.995 \% \mathrm{CI}=(9.14-39.3)$ vs. $30.0 \quad(95 \%$ $\mathrm{CI}=20.1-51.7)$ months, $p=0.0420]$.

In addition, we compared PFS and OS according to TI and dose reduction. Twenty-two patients required treatment reduction without interruption, and the patient background is shown in Table II. When compared to the patients with dose reduction, PFS and OS were shorter in patients with TI, although the statistical difference was not significant (Figure 3). Interestingly, there was no significant difference in PFS or OS between patients with a dose reduction and those without modification $[\mathrm{PFS}=14.3$ (95\% CI=6.18-26.2) months, $p=0.655$; $\mathrm{OS}=30.0$ (95\% CI=11.0-not reached) months, $p=0.828]$.

Furthermore, we evaluated PFS and OS according to whether patients restarted sunitinib treatment after their interruption (Figure 4). Among the 38 patients with TI, sunitinib therapy was restarted in 24 . For the other 14 patients, therapy for two was changed to nivolumab and that for the others to supportive care. Median PFS and OS were significantly longer for the patients that restarted sunitinib than for those that discontinued sunitinib [PFS $=9.57(95 \%$ $\mathrm{CI}=6.15-13.9) \quad$ vs. $2.53 \quad$ (95\% $\mathrm{CI}=0.79-3.19 \quad p<0.0001$; $\mathrm{OS}=26.6(95 \% \mathrm{CI}=150$-not reached) $v s .4 .54(95 \% \mathrm{CI}=1.51-$ 20.2), $p=0.0003$, respectively]. 
A

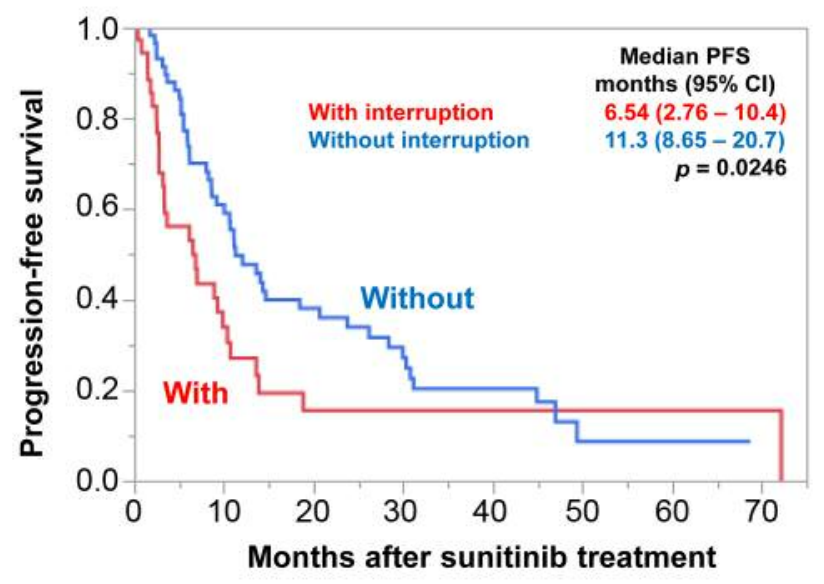

B

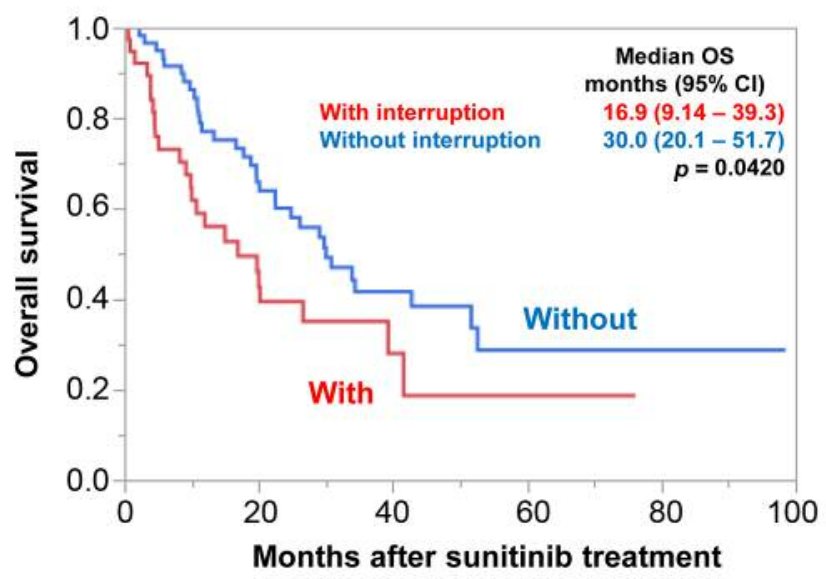

Figure 2. Progression-free (PFS) (A) and overall (OS) (B) survival according to immediate treatment interruption. PFS and OS were significantly shorter for patients with immediate treatment interruption. CI: Confidence interval.

Table II. Patient background (treatment modifications).

\begin{tabular}{|c|c|c|c|c|}
\hline & $\begin{array}{l}\text { Treatment interruption } \\
\qquad(\mathrm{n}=38)\end{array}$ & $\begin{array}{l}\text { Dose reduction } \\
\quad(\mathrm{n}=22)\end{array}$ & $\begin{array}{l}\text { No modification } \\
\qquad(\mathrm{n}=37)\end{array}$ & $p$-Value \\
\hline \multicolumn{5}{|l|}{ Age } \\
\hline$\geq 65$ Years & $22(57.9 \%)$ & $10(45.5 \%)$ & $15(40.5 \%)$ & 0.307 \\
\hline \multicolumn{5}{|l|}{ Gender } \\
\hline Male & $21(55.3 \%)$ & $17(77.3 \%)$ & $29(78.4 \%)$ & 0.0613 \\
\hline \multicolumn{5}{|l|}{ Histopathology } \\
\hline Clear-cell carcinoma & $24(63.2 \%)$ & $15(68.2 \%)$ & $31(83.8 \%)$ & $0.123^{*}$ \\
\hline Non-clear cell carcinoma & $14(36.8 \%)$ & $7(31.8 \%)$ & $6(16.2 \%)$ & \\
\hline Papillary renal cell carcinoma type II & $3(7.89 \%)$ & $1(4.55 \%)$ & $1(2.70 \%)$ & \\
\hline Clear-cell carcinoma with spindle cells & $6(15.8 \%)$ & $1(4.55 \%)$ & $1(2.70 \%)$ & \\
\hline Other/unknown & $5(13.2 \%)$ & $5(22.7 \%)$ & $4(10.8 \%)$ & \\
\hline \multicolumn{5}{|l|}{ MSKCC risk group } \\
\hline Favorable & $6(15.8 \%)$ & $2(9.09 \%)$ & $7(18.9 \%)$ & 0.622 \\
\hline Intermediate & $27(71.1 \%)$ & $18(81.8 \%)$ & $23(62.2 \%)$ & \\
\hline Poor & $5(13.2 \%)$ & $2(9.09 \%)$ & $7(18.9 \%)$ & \\
\hline \multicolumn{5}{|l|}{ Prior nephrectomy } \\
\hline Yes & $32(84.2 \%)$ & $19(86.4 \%)$ & $34(91.9 \%)$ & 0.588 \\
\hline \multicolumn{5}{|l|}{ Treatment schedule } \\
\hline 4-weeks-on/2-weeks-off & $16(42.1 \%)$ & $5(22.7 \%)$ & $9(24.3 \%)$ & 0.160 \\
\hline \multicolumn{5}{|l|}{ Initial dose } \\
\hline $50 \mathrm{mg}$ & $11(29.0 \%)$ & $10(45.5 \%)$ & $9(24.3 \%)$ & \\
\hline \multicolumn{5}{|l|}{$0.0390 * *$} \\
\hline $37.5 \mathrm{mg}$ & $19(50.0 \%)$ & $12(54.6 \%)$ & $19(51.4 \%)$ & \\
\hline $25 \mathrm{mg}$ & $8(21.1 \%)$ & 0 & $9(24.3 \%)$ & \\
\hline \multicolumn{5}{|l|}{ Site of metastasis } \\
\hline Multiple & $20(52.6 \%)$ & $12(54.6 \%)$ & $16(43.2 \%)$ & 0.621 \\
\hline \multicolumn{5}{|l|}{ Liver metastasis } \\
\hline Yes & $7(18.4 \%)$ & $3(13.6 \%)$ & $3(8.11 \%)$ & 0.423 \\
\hline \multicolumn{5}{|l|}{ RDI within initial 2 cycles } \\
\hline Median $(95 \% \mathrm{CI}))$ & $52.7(37.5-62.5)$ & $71.9(61.7-81.3)$ & $75.0(75.0-93.8)$ & $<0.0001$ \\
\hline \multicolumn{5}{|l|}{ Follow-up period } \\
\hline Median (IQR) & $12.7(4.57-25.9)$ & $24.0(9.55-45.5)$ & $24.5(12.4-35.3)$ & 0.0160 \\
\hline
\end{tabular}

CI: Confidence intervaI; IQR: interquartile range; MSKCC: Memorial Sloan Kettering Cancer Center. *Clear-cell carcinoma vs. non-clear-cell carcinoma. $* * \geq 37.5 v s .<37.5 \mathrm{mg}$. 
A

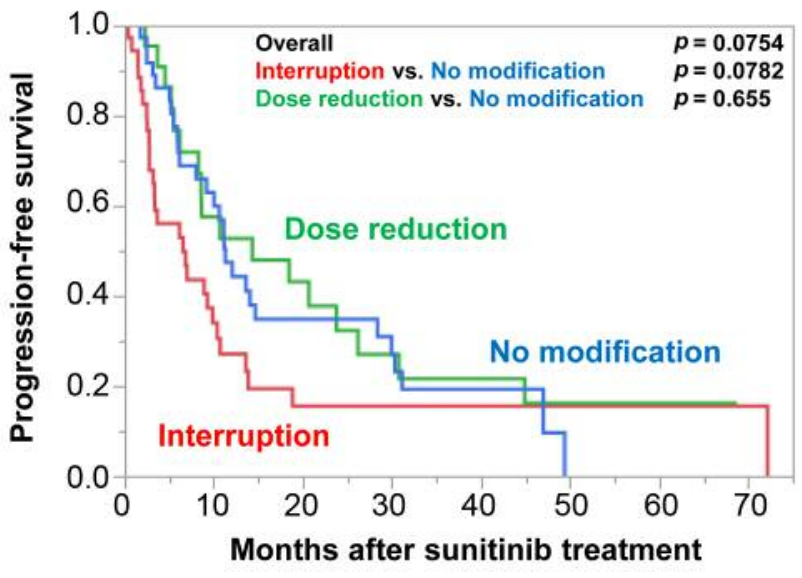

Median PFS months $(95 \% \mathrm{Cl})$

Interruption Dose reduction No modification
$6.54(2.76-10.4)$

$11.3(8.02-28.4)$
$14.3(6.18-26.2)$
B

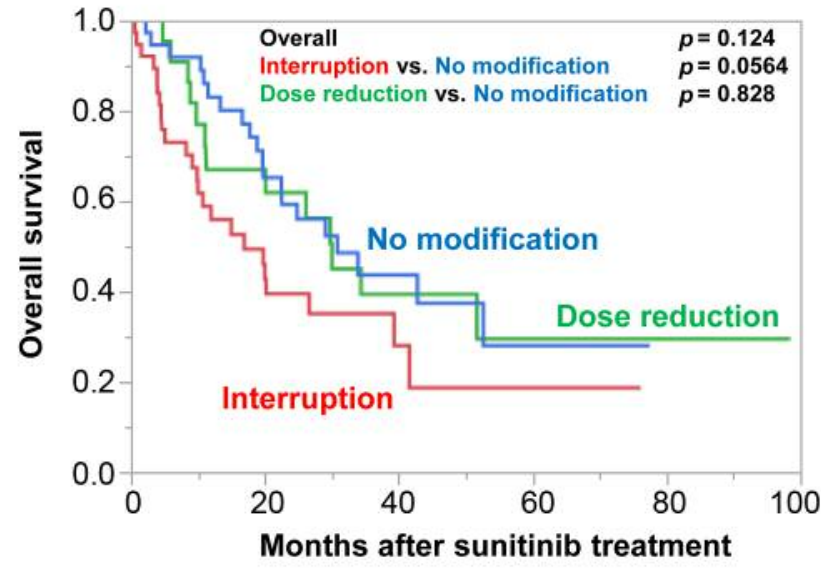

Median OS months $(95 \% \mathrm{Cl})$

$16.9(9.14-39.3)$

30.0 (11.0 - not reached)

30.8 (19.7 - 52.6)

Figure 3. Progression-free (PFS) (A) and overall $(O S)(B)$ survival according to treatment modification. PFS and OS were shorter for patients with immediate treatment interruption compared to those with dose reduction and those without treatment modification, although the statistical difference was not significant. There was no difference in survival between the patients with dose reduction and those without treatment modification. CI: Confidence interval.

A

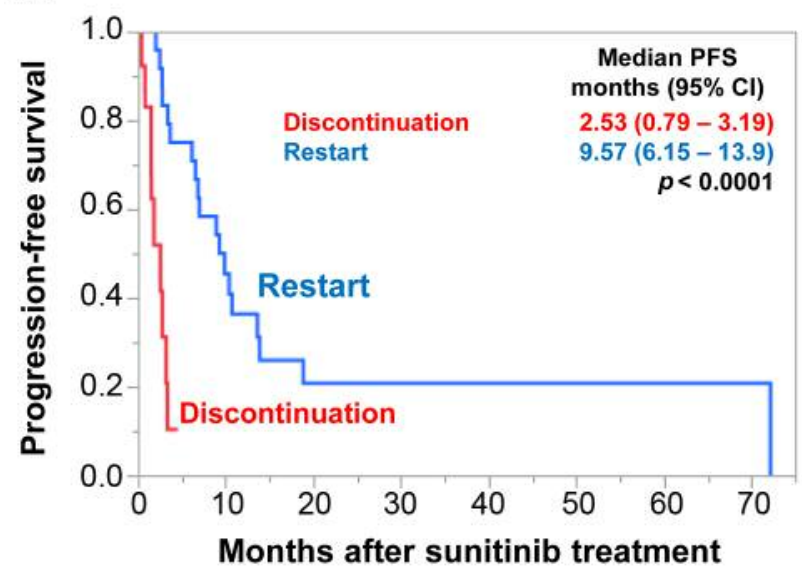

B

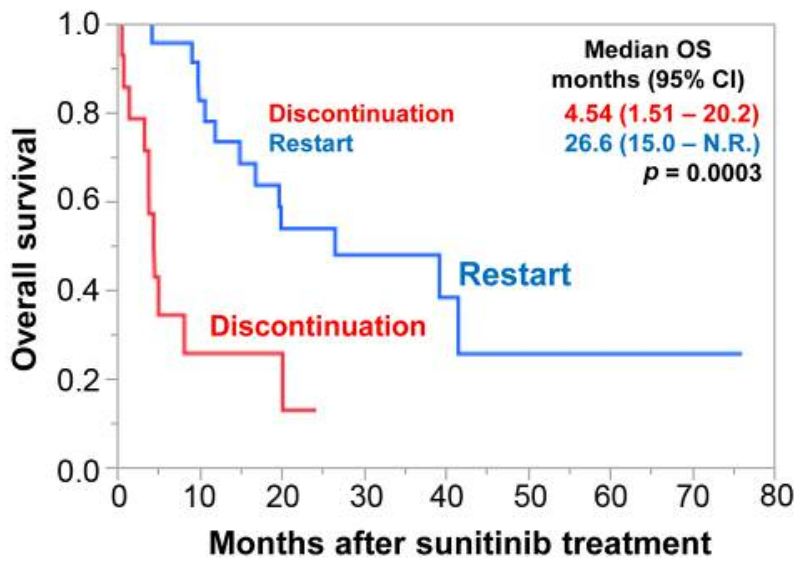

Figure 4. Progression-free (PFS) (A) and overall $(O S)(B)$ survival according to restart of treatment after immediate treatment interruption. PFS and $O S$ were significantly shorter in patients who did not restart treatment. CI: Confidence interval.

Prognostic factors of PFS and OS. Univariate analysis of PFS showed that non-clear cell carcinoma histopathology, MSKCC poor-risk group, liver metastasis, and TI were significant factors in poorer overall outcome (all $p<0.05$; Table III). Multivariate analysis showed that TI was an independent factor $\quad(\mathrm{HR}=1.93, \quad 95 \% \quad \mathrm{CI}=1.15-3.22$; $p=0.0141)$, together with non-clear cell carcinoma histopathology $(p=0.0097)$ and the MSKCC poor-risk group $(p=0.0250)$. Univariate analysis of OS showed that non-clear cell carcinoma histopathology, MSKCC poor-risk group liver 
in vivo $33: 2153-2160(2019)$

Table III. Univariate and multivariate analysis for progression-free survival (PFS) and overall survival (OS) according to treatment interruption .

\begin{tabular}{|c|c|c|c|c|c|c|c|c|}
\hline & \multicolumn{4}{|c|}{ PFS } & \multicolumn{4}{|c|}{ OS } \\
\hline & \multicolumn{2}{|c|}{ Univariate } & \multicolumn{2}{|c|}{ Multivariate } & \multicolumn{2}{|c|}{ Univariate } & \multicolumn{2}{|c|}{ Multivariate } \\
\hline & $\operatorname{HR}(95 \% \mathrm{CI})$ & $p$-Value & $\operatorname{HR}(95 \% \mathrm{CI})$ & $p$-Value & $\operatorname{HR}(95 \% \mathrm{CI})$ & $p$-Value & $\operatorname{HR}(95 \% \mathrm{CI})$ & $p$-Value \\
\hline \multicolumn{9}{|l|}{ Age } \\
\hline$\geq 65$ vs. $<65$ years & $0.92(0.58-1.47)$ & 0.738 & & & $1.17(0.70-1.98)$ & 0.548 & & \\
\hline \multicolumn{9}{|l|}{ Gender } \\
\hline Male vs. female & $0.69(0.42-1.16)$ & 0.159 & & & $0.63(0.37-1.10)$ & 0.104 & & \\
\hline \multicolumn{9}{|l|}{ Histopathology } \\
\hline $\begin{array}{l}\text { Clear-cell carcinoma } v s \text {. } \\
\text { non-clear cell carcinoma }\end{array}$ & $0.39(0.23-0.66)$ & 0.0006 & $0.48(0.28-0.83)$ & 0.0097 & $0.40(0.23-0.71)$ & 0.0025 & $0.44(0.25-0.82)$ & 0.0096 \\
\hline MSKCC risk group & & 0.0013 & & 0.0070 & & 0.0005 & & 0.0013 \\
\hline Favorable $v s$. intermediate & $0.42(0.19-0.85)$ & 0.0130 & $0.50(0.21-1.02)$ & 0.0556 & $0.43(0.16-0.95)$ & 0.0364 & $0.47(0.17-1.09)$ & 0.0796 \\
\hline Poor vs. intermediate & $2.22(1.12-4.06)$ & 0.0242 & $2.33(1.12-4.56)$ & 0.0250 & $2.98(1.47-5.62)$ & 0.0034 & $3.00(1.45-5.80)$ & 0.0039 \\
\hline \multicolumn{9}{|l|}{ Treatment schedule } \\
\hline 2-weeks-on/1-week-off & $1.12(0.67-1.81)$ & 0.664 & & & $1.10(0.62-1.89)$ & 0.727 & & \\
\hline $\begin{array}{l}\text { Initial dose } \\
\geq 37.5 \mathrm{vs} .<37.5 \mathrm{mg}\end{array}$ & $0.54(0.30-1.04)$ & 0.0642 & & & $0.74(0.40-1.51)$ & 0.390 & & \\
\hline \multicolumn{9}{|l|}{ Site of metastasis } \\
\hline Multiple $v s$. solitary & $1.27(0.79-2.02)$ & 0.321 & & & $1.54(0.91-2.62)$ & 0.107 & & \\
\hline \multicolumn{9}{|l|}{ Liver metastasis } \\
\hline With $v s$. without & $2.40(1.14-4.56)$ & 0.0229 & $1.89(0.88-3.67)$ & 0.0997 & $3.45(1.66-6.63)$ & 0.0016 & $3.11(1.48-6.04)$ & 0.0039 \\
\hline \multicolumn{9}{|l|}{ Treatment interruption } \\
\hline With $v s$. without & $1.73(1.05-2.78)$ & 0.0308 & $1.93(1.15-3.22)$ & 0.0141 & $1.72(1.00-2.91)$ & 0.0486 & $2.09(1.20-3.62)$ & 0.0102 \\
\hline
\end{tabular}

CI: Confidence intervaI; HR: hazard ratio; MSKCC: Memorial Sloan Kettering Cancer Center.

metastasis, and TI were significant factors (all $p<0.05$ ). Multivariate analysis showed that TI was an independent factor $(\mathrm{HR}=2.09,95 \% \mathrm{CI}=1.20-3.62 ; p=0.0102)$, together with non-clear cell carcinoma histopathology $(p=0.0096)$, MSKCC poor risk group $(\mathrm{HR}=3.00,95 \% \mathrm{CI}=1.45-5.80$; $p=0.0039)$, and liver metastasis $(\mathrm{HR}=3.11,95 \% \mathrm{CI}=1.48$ 6.04; $p=0.0039$ ) (Table III).

DLTs and treatment modifications. Table IV shows the individual AEs inducing treatment interruption. Grade 3 or higher AEs developed in 28 out of the 38 patients (73.7\%). The most frequent $\mathrm{AE}$ was thrombocytopenia [grade $\geq 3,11$ patients $(28.9 \%)$ ], followed by leukocytopenia [grade $\geq 3$, six patients $(15.8 \%)]$.

\section{Discussion}

This retrospective study showed that PFS and OS were significantly shorter in patients with TI within the initial two cycles after first-line sunitinib treatment for mRCC. Multivariate analyses further showed that TI was an independent factor for shorter PFS and OS. Moreover, rather than dose reduction, TI was likely to be associated with
Table IV. Individual dose-limiting toxicities inducing treatment interruption $(n=38)$.

\begin{tabular}{lcc}
\hline & \multicolumn{2}{c}{ Grade, $\mathrm{n}$} \\
\cline { 2 - 3 } Adverse event & $\leq 2$ & $\geq 3$ \\
\hline Fatigue & 0 & 1 \\
Hand-foot syndrome & 1 & 0 \\
Thrombocytopenia & 2 & 11 \\
Anemia & 0 & 1 \\
Leukocytopenia & 1 & 6 \\
Diarrhea & 0 & 0 \\
Acute kidney injury & 0 & 0 \\
AST/ALT increased & 0 & 2 \\
Fever & 2 & 1 \\
Dysgeusia & 1 & 0 \\
Vomiting & 3 & 0 \\
Nausea & 2 & 0 \\
Anorexia & 3 & 1 \\
Infection & 0 & 2 \\
Hyperkalemia & 0 & 2 \\
Ileal perforation & 0 & 1 \\
Lipase increased & 0 & 2 \\
Total, n (\%) & $10(26.3 \%)$ & $28(73.7 \%)$ \\
\hline
\end{tabular}

AST/ALT: Aspartate aminotransferase; ALT: alanine aminotransferase. 
shorter survival. Furthermore, the most frequent AEs leading to TI were hematotoxicity in our cases.

The RDI may need to be included in the multivariate analysis owing to the possibility of its significance for survival. However, because this is a confounding factor with the presence of TI (Table I), these two factors were not analyzed together in the multivariate analysis. Previous studies indicated that an efficient RDI was needed to maintain therapeutic efficacy in sunitinib treatment (7-9). Porta et al. reported that an RDI of less than $70 \%$ during the initial three cycles was associated with significantly shorter OS in sunitinib treatment (9). In another study, Kawashima et al. suggested that an RDI of $60 \%$ or higher within the first month was important for PFS prolongation (7). We also previously reported that an RDI of $60 \%$ or higher during the initial cycle was required to maintain therapeutic efficacy (6). However, the number of studies investigating the relationship between modification type (i.e., TI or dose reduction) and survival is limited. In this context, the current study suggested the negative impact of TI, not dose reduction, developed within the initial phase of sunitinib therapy.

Importantly, because sufficient RDI within the initial phase is also required as described above, an excessive initial dose reduction in order to avoid TI is not allowed. That is, our data suggest the importance of careful management so as not to cause TI while maintaining the RDI. In cases with TI development or RDI decrease in the initial phase, a conversion to other targeted agent or therapy with different modes of action, such as immune checkpoint inhibitors, may be an effective option.

The most frequent AE causing TI was hematotoxicity, including thrombocytopenia and leukocytopenia, in our analysis. Indeed, previous studies showed hematotoxicity that developed in the early phase reduced therapeutic efficacy and survival rates $(14,15)$. Unfortunately, hematotoxicity is generally difficult to treat or prevent by symptomatic treatment. Therefore, careful scheduling or dosage management is required to properly reduce the sunitinib dose to avoid interrupting administration, even in cases with DLT development.

This study had several limitations. Firstly, this study was retrospective in nature, performed at a single center, and had a small sample size. Thus, unavoidable biases exist in any findings. In addition, not all AEs may have been recognized, and the unrecorded AEs might have affected our analyses. SecondIy, the majority of patients $(69.1 \%)$ who followed an alternative 2-weeks-on/1-week-off treatment schedule reported greater comfort and tolerability than those on the standard schedule $(11,16,17)$. Thus, this alternative schedule can affect patient tolerability analyses. Finally, not all treatment modification decisions were based on guidelines because of the retrospective nature of this study.
In conclusion, this retrospective study showed that immediate TI resulted in a significantly negative effect on survival of patients under sunitinib treatment for mRCC. Therefore, the careful monitoring of patient tolerability is required in order to maintain therapeutic efficacy in the early phase of sunitinib treatment.

\section{Acknowledgements}

The Authors thank Ms. Nobuko Hata (Department of Urology, Tokyo Women's Medical University) for her secretarial work.

\section{Conflicts of Interest}

Tsunenori Kondo received honoraria from Pfizer and Ono Pharmaceutical. All other Authors have no conflicts of interest to declare.

\section{Authors' Contributions}

Ryo Ishiyama, Hiroki Ishihara, and Tsunenori Kondo designed the study. Ryo Ishiyama, Hiroki Ishihara, Tsunenori Kondo, and Toshio Takagi interpreted the data and wrote the manuscript. Tsunenori Kondo, Toshio Takagi, Kazuhiko Yoshida, Junpei Iizuka, Hirohito Kobayashi, Masayoshi Okumi, Hideki Ishida, and Kazunari Tanabe collected the data.

\section{References}

1 Boegemann M, Hubbe M, Thomaidou D, Blackburn S, BentEnnakhil N, Wood R and Bargo D: Sunitinib treatment modification in first-line metastatic renal cell carcinoma: Analysis of the STAR-TOR Registry. Anticancer Res 38: 64136422, 2018. PMID: 30396966. DOI: 10.21873/anticanres.13002

2 Motzer RJ, Jonasch E, Agarwal N, Bhayani S, Bro WP, Chang SS, Choueiri TK, Costello BA, Derweesh IH, Fishman M, Gallagher TH, Gore JL, Hancock SL, Harrison MR, Kim W, Kyriakopoulos C, LaGrange C, Lam ET, Lau C, Michaelson MD, Olencki T, Pierorazio PM, Plimack ER, Redman BG, Shuch B, Somer B, Sonpavde G, Sosman J, Dwyer M and Kumar R: Kidney Cancer, Version 2.2017, NCCN Clinical Practice Guidelines in Oncology. JNCCN 15: 804-834, 2017. PMID: 28596261. DOI: 10.6004/jnccn.2017.0100

3 Vazquez S, Leon L, Fernandez O, Lázaro M, Grande E and Aparicio L: Sunitinib: the first to arrive at first-line metastatic renal cell carcinoma. Adv Ther 29: 202-217, 2012. PMID: 22328304. DOI: 10.1007/s12325-011-0099-9

4 Motzer RJ, Hutson TE, Tomczak P, Michaelson MD, Bukowski RM, Rixe O, Oudard S, Negrier S, Szczylik C, Kim ST, Chen I, Bycott PW, Baum CM and Figlin RA: Sunitinib versus interferon alfa in metastatic renal-cell carcinoma. N Engl J Med 356: 115-124, 2007. PMID: 17215529. DOI: 10.1056/ NEJMoa065044

5 Motzer RJ, Hutson TE, Cella D, Reeves J, Hawkins R, Guo J, Nathan P, Staehler M, de Souza P, Merchan JR, Boleti E, Fife $\mathrm{K}$, Jin J, Jones R, Uemura H, De Giorgi U, Harmenberg U, Wang J, Sternberg CN, Deen K, McCann L, Hackshaw MD, Crescenzo R, Pandite LN and Choueiri TK: Pazopanib versus 
sunitinib in metastatic renal-cell carcinoma. N Engl J Med 369: 722-731, 2013. PMID: 23964934. DOI: 10.1056/NEJMoa 1303989

6 Ishihara $\mathrm{H}$, Takagi $\mathrm{T}$, Kondo $\mathrm{T}$, Iwamoto $\mathrm{K}$, Tachibana H, Yoshida K, Omae K, Iizuka J, Kobayashi H and Tanabe K: Decreased relative dose intensity during the early phase of treatment impacts the therapeutic efficacy of sunitinib in metastatic renal cell carcinoma. Jpn J Clin Oncol 48: 667-672, 2018. PMID: 29860353. DOI: 10.1093/jjco/hyy078

7 Kawashima A, Tsujimura A, Takayama H, Arai Y, Nin M, Tanigawa G, Yasunaga Y, Mukai M, Uemura M, Nakai Y, Nishimura $\mathrm{K}$ and Nonomura $\mathrm{N}$ : Importance of continuing therapy and maintaining one-month relative dose intensity in sunitinib therapy for metastatic renal cell carcinoma. Med Oncol 29: 3298-3305, 2012. PMID: 22544539. DOI: 10.1007/s12032012-0236-6

8 Arakawa-Todo M, Yoshizawa T, Zennami K, Nishikawa G, Kato Y, Kobayashi I, Kajikawa K, Yamada Y, Matsuura K, Tsukiyama I, Saito H, Hasegawa T, Nakamura $\mathrm{K}$ and Sumitomo M: Management of adverse events in patients with metastatic renal cell carcinoma treated with sunitinib and clinical outcomes. Anticancer Res 33: 5043-3050, 2013. PMID: 24222148.

9 Porta C, Levy A, Hawkins R, Castellano D, Bellmunt J, Nathan P, McDermott R, Wagstaff J, Donnellan P, McCaffrey J, Vekeman F, Neary MP, Diaz J, Mehmud F and Duh MS: Impact of adverse events, treatment modifications, and dose intensity on survival among patients with advanced renal cell carcinoma treated with firstline sunitinib: A medical chart review across ten centers in five European countries. Cancer Med 3: 1517-1526, 2014. PMID: 25045157. DOI: $10.1002 / \mathrm{cam} 4.302$

10 Iwamoto K, Ishihara H, Takagi T, Kondo T, Yoshida K, Iizuka J and Tanabe K: Evaluation of relative dose intensity during the early phase of first-line sunitinib treatment using a 2-week-on/1week-off regimen for metastatic renal cell carcinoma. Med Oncol 35: 78, 2018. PMID: 29687160. DOI: 10.1007/s12032018-1139-y

11 Kondo T, Takagi T, Kobayashi H, Iizuka J, Nozaki T, Hashimoto Y, Ikezawa E, Yoshida K, Omae K and Tanabe K: Superior tolerability of altered dosing schedule of sunitinib with 2-weekson and 1-week-off in patients with metastatic renal cell carcinoma--comparison to standard dosing schedule of 4-weekson and 2-weeks-off. Jpn J Clin Oncol 44: 270-277, 2014. PMID: 24474815. DOI: $10.1093 / \mathrm{jjco} / \mathrm{hyt} 232$
12 Ikeda T, Ishihara H, Takagi T, Kondo T, Yoshida K, Iizuka J and Tanabe K: Prognostic impact of the components of progressive disease on survival after first-line tyrosine kinase inhibitor therapy for metastatic renal cell carcinoma. Targeted Oncol 13: 379-387, 2018. PMID: 29785576. DOI: 10.1007/s11523-0180569-y

13 National Cancer Institute: Common Terminology Criteria for Adverse Events (CTCAE) Common Terminology Criteria for Adverse Events v4.0 (CTCAE), 2009.

14 Motzer RJ, Hutson TE, Tomczak P, Michaelson MD, Bukowski RM, Oudard S, Negrier S, Szczylik C, Pili R, Bjarnason GA, Garcia-del-Muro X, Sosman JA, Solska E, Wilding G, Thompson JA, Kim ST, Chen I, Huang $X$ and Figlin RA: Overall survival and updated results for sunitinib compared with interferon alpha in patients with metastatic renal cell carcinoma. J Clin Oncol 27: 3584-3590, 2009. PMID: 19487381. DOI: 10.1200/JCO.2008.20.1293

15 Tomita Y, Shinohara N, Yuasa T, Fujimoto H, Niwakawa M, Mugiya S, Miki T, Uemura H, Nonomura N, Takahashi M, Hasegawa Y, Agata N, Houk B, Naito S and Akaza H: Overall survival and updated results from a phase II study of sunitinib in Japanese patients with metastatic renal cell carcinoma. Jpn J Clin Oncol 40: 1166-1172, 2010. PMID: 20713418. DOI: $10.1093 / \mathrm{jjco} / \mathrm{hyq} 146$

16 Atkinson BJ, Kalra S, Wang X, Bathala T, Corn P, Tannir NM and Jonasch E: Clinical outcomes for patients with metastatic renal cell carcinoma treated with alternative sunitinib schedules. J Urol 191: 611-618, 2014. PMID: 24018239. DOI: 10.1016/ j.juro.2013.08.090

17 Najjar YG, Mittal K, Elson P, Wood L, Garcia JA, Dreicer R and Rini BI: A 2 weeks on and 1 week off schedule of sunitinib is associated with decreased toxicity in metastatic renal cell carcinoma. Eur J Cancer 50: 1084-1089, 2014. PMID: 24559686. DOI: $10.1016 /$ j.ejca.2014.01.025
Received August 3, 2019

Revised August 31, 2019

Accepted September 9, 2019 